\title{
CIDADE E ESPAÇO PÚBLICO: política de revitalização urbana em Belo Horizonte
}

\author{
Juliana Gonzaga Jayme* \\ Magda de Almeida Neves*
}

\begin{abstract}
Este artigo objetiva discutir se, e em que medida, a construção dos shoppings populares - uma das ações do programa Centro Vivo ${ }^{1}$ - que objetivou retirar os camelôs das ruas do Hipercentro de Belo Horizonte, contribuiu para a maximização do uso mais heterogêneo desses espaços. Para tanto, o texto será dividido em quatro tópicos. No primeiro, far-se-á um histórico da presença dos vendedores ambulantes em Belo Horizonte, com o intuito de situá-los no tempo e, ao mesmo tempo, refletir sobre sua apropriação do centro da cidade, mais recentemente. No segundo, discutir-se-ão a ideia e o ideal de espaço público, conforme pensado na modernidade. Em seguida, a reflexão se volta para o espaço público na sociedade contemporânea, a partir das políticas de revitalização em geral - comuns, a partir do final dos anos 1980 -, e o caso de Belo Horizonte. Por fim, na busca de uma conclusão, retomar-se-á a relação entre os sujeitos que foram transferidos para os shoppings populares - os camelôs - e o cenário em questão: o centro de Belo Horizonte.

PALAVRAS-CHAVE: cidade, espaço público, revitalização urbana, shoppings populares.
\end{abstract}

\section{CAMELÔS EM BELO HORIZONTE: esboço de um histórico}

Desde a fundação da cidade, existem vendedores ambulantes em Belo Horizonte. Segundo Castro (2003), por muito tempo, eles foram fundamentais, porque a capital tinha um problema crônico de abastecimento, e os ambulantes comercializavam produtos de subsistência. Além deles, havia os mascates, que vendiam, em domicílio, produtos manufaturados, o que causava problema para o setor público, porque eram vistos com certa desconfiança, por venderem produtos a baixo preço e, dessa forma, concorrer, de forma desleal, com o restante do comércio. Assim, em 1908, instituiu-se uma taxa de

* Doutora em Ciências Sociais pela UNICAMP. Professora e pesquisadora do Programa de Pós-graduação em Ciências Sociais e de Antropologia dos cursos de Şerviço Social e Publicidade e Propaganda da PUC-MG.

Pontifícia Universidade Católica de Minas Gerais. Rua Itaú, 505 - Dom Bosco. Cep: 30730-280 - Belo Horizonte, MG Brasil.julianajayme@pucminas.br

* * Doutora em Sociologia. Professora Professora do Programa de Pós Graduação em Ciências Sociais da PUC-MG. mneves@pucminas.br

${ }^{1}$ Programa de Recuperação do Centro da cidade de Belo Horizonte. imposto aos mascates, além de multa àqueles que não tivessem licença da prefeitura. Castro mostra como, desde então, esses trabalhadores eram vistos com alguma animosidade:

... os ambulantes e mascates ficaram malvistos pelo poder público, sendo acusados de enganar o Estado e os consumidores, através da sonegação de impostos e pelo fornecimento de mercadorias de tipo inferior na qualidade e quantidade.” (Castro, 2003, p.33).

Apesar de a presença dos ambulantes em Belo Horizonte remontar à fundação da cidade, foi apenas no fim dos anos 1960 que tal comércio ocupou o centro da cidade. ${ }^{2}$ Nos anos 1970, com a região central muito adensada e, por isso mesmo, deteriorada, a Savassi ${ }^{3}$ se tornou uma

${ }^{2}$ Desde o início do século XX, porém, os ambulantes são vistos como um problema para o poder público e, portanto, são alvo de legislação que os regulamenta (Castro, 2003; Zambelli, 2006).

${ }^{3}$ Savassi era o nome de uma padaria que se situava à Praça Diogo de Vasconcelos, no bairro Funcionários. Essa praça passou a ser chamada, informalmente, de Savassi, nos anos 1950, e, com a consolidação da área como uma nova centralidade, acabou se tornando um bairro. Em 14 de março de 1991, a Prefeitura de Belo Horizonte, por meio da Lei $n^{\circ} 5872$, reconheceu e estabeleceu a Região da Savassi. (www.descubraminas.com.br) 
centralidade alternativa, abrigando o comércio mais elitizado, enquanto o centro passou a ser visto como um local impróprio para a elite, posto que ali circulavam as mais diferentes camadas sociais (Lemos, 2003). Nessa época, o comércio da região central já era menos sofisticado e a presença dos camelôs significativa (Castro, 2003; Lemos, 2003; Zambelli, 2006).

A partir dos anos 1980, entretanto, houve um forte aumento do comércio ambulante na região central de Belo Horizonte, o que, certamente, se vincula ao contexto da época. Como se sabe, com a reestruturação produtiva, que modificou a relação de assalariamento típica da organização urbano-industrial do trabalho, houve crescimento do desemprego e, com isso, muitos trabalhadores buscaram, no setor informal, alternativas de renda. A atividade de camelôs e de toreros $^{4}$ foi uma das que teve intenso crescimento nessa época e não só em Belo Horizonte, mas também em outras capitais. Ver, por exemplo, Frúgoli (1999), ${ }^{5}$ Gonçalves e Thomaz Júnior (2002), Durães (2007).

Assistiu-se, nas décadas de 1980 e 1990, a uma ocupação do espaço da região central pelos vendedores ambulantes de forma bem mais ostensiva. As calçadas se transformaram em verdadeiros mercados, onde se ofereciam produtos variados e a preços bem inferiores aos vendidos nas lojas. Os lojistas se sentiram prejudicados, já que, para eles, a concorrência era desleal e, além disso, as barracas eram posicionadas em frente às lojas, ocultando suas fachadas. Essas atividades, então, se tornaram, mais uma vez, alvo de ações públicas que tentaram conter seu aumento, além de buscar a manutenção da ordem na região central. Em agosto de 1984, foi sanciona-

${ }^{4}$ Os primeiros são aqueles que têm garantias legais para o exercício de suas atividades, oficializados pelo Departamento de Controle Urbano, por meio de processos de licitação. Os toreros atuam nas ruas com licença provisória, em áreas alternativas "minifeiras " criadas pela Prefeitura de Belo Horizonte (Lemos, 2003).

${ }^{5}$ Frúgoli (1999) aponta, para o caso de São Paulo, não só o crescimento da categoria, mas também uma mudança do perfil desses trabalhadores; desde os anos 1980, operários demitidos das indústrias e mesmo outros profissionais sem emprego, como bancários e engenheiros, passaram a trabalhar como camelôs. da a Lei Municipal $n^{\circ} 3.841$, com o objetivo de organizar as atividades informais, conferindo aos camelôs licença para o exercício do seu trabalho. Essa lei foi importante para a categoria, na medida em que lhe garantiu o espaço da rua como local de trabalho, tanto que ela foi sancionada depois de muita mobilização dos próprios camelôs (Castro, 2003; Zambelli, 2006).

Apesar da sanção da Lei ${ }^{\circ} 3.841$, as ruas da região central de Belo Horizonte se tornaram, em alguns pontos, difíceis até para os transeuntes andarem, posto que ambulantes não-licenciados - os toreros - dividiam espaço com os camelôs; ou seja, a lei criada para disciplinar o espaço e garantir a rua como local de trabalho, não teve a eficácia desejada. Embora, nessa época, camelôs e agentes da Prefeitura concordassem com o fato de que o centro estava cada vez mais desorganizado, não houve consenso em relação a como resolver essa situação. Em 1993, a Prefeitura cadastrou novos camelôs, com área delimitada de atuação, mas definiu uma região de tolerância zero em relação ao comércio de rua. Paralelamente, abriu espaço para os toreros na Rua Tamoios.

Segundo Figueiredo e Morais (2004), pouco a pouco, os ambulantes ocuparam a área de tolerância zero e ignoraram outras determinações da prefeitura para o licenciamento, como a distância entre as barracas. Em 2004, havia, de acordo com as autoras, mais de dois mil vendedores ambulantes - e a maioria sem autorização da Prefeitura de Belo Horizonte - no centro da cidade, o que incomodava não só os lojistas, mas também os transeuntes.

Como foi apontado, houve tentativa de regulamentação dos comerciantes de rua, em Belo Horizonte, desde o início do século XX. Pode-se dizer, no entanto, que a ocupação "desenfreada" nas últimas décadas do século XX, pelos camelôs e toreros, aliada a uma discussão mundial sobre a importância de requalificação de antigas áreas centrais, contribuíram para que a Prefeitura de Belo Horizonte buscasse uma solução no que se refere ao espaço de trabalho desses ven- 
dedores. A ideia era definir área própria ao comércio ambulante, ainda nas ruas e, paralelamente, construir shoppings populares, para onde, num futuro próximo, todos os camelôs seriam transferidos (Neves, 2006; Jayme, 2006; Zambelli, 2006). ${ }^{6}$ Entre 2003 e 2005, segundo dados da PBH, foram transferidos 1772 camelôs e toreros para shoppings populares, Oiapoque, ${ }^{7}$ Tupinambás, Xavante Pop Shopping, Caetés, Araguari e Tocantins, sendo que esse último é administrado pela prefeitura, diferentemente dos outros, que são geridos pela iniciativa privada.

A criação dos shoppings populares em Belo Horizonte foi resolvida em 22 de agosto de 2003, por meio do Decreto ${ }^{\circ} 11.424$. O primeiro shopping inaugurado foi o Oiapoque - localizado à Avenida Oiapoque, 176 -, que começou a funcionar em agosto do mesmo ano. Seu prédio, local onde anteriormente funcionou uma fábrica de cerveja, destaca-se do conjunto arquitetônico da região e foi tombado, em 1991, pelo Conselho Deliberativo do Patrimônio Histórico do Município.

A região em torno desse shopping era considerada como perigosa e degradante. O espaço era frequentado por um público marginalizado, como alcoólatras, prostitutas, traficantes e ladrões, o que poderia limitar a frequência mais assídua dos possíveis consumidores ao shopping, especialmente daqueles provenientes da classe média. Isso não aconteceu, porém, já que o Oiapoque recebe, inclusive, público da classe média, além de ser frequentado por outros segmentos sociais, tendo como consumidores outros "empreendedores populares", ${ }^{8}$ que compram no atacado.

${ }^{6}$ Os camelôs licenciados (aqueles que participaram das mobilizações que culminaram na Lei n 3841) sentiram-se lesados com a forma como se deu a desocupação de parte da área central, no fim dos anos 1990, início dos 2000 , porque, em sua opinião, eles teriam perdido o espaço que lhes fora garantido com a Lei $n^{\circ} 3841$. A Prefeitura, por outro lado, fez um balanço positivo dessa medida, pois teria atingido o objetivo de solucionar o problema do centro.

${ }^{7}$ Chamado de Shopping Oi.

${ }^{8}$ De acordo com o Regimento da Prefeitura Municipal de Belo Horizonte, ao ser transferido para os shoppings populares, o camelô passa a ser denominado empreendedor popular. Pelo regulamento, empreendedor popular é a pessoa
O shopping Oiapoque tem diversos setores, distribuídos em vários corredores e identificados por cores, algumas escadas e rampas, mas com sinalização, de certo modo, imprecisa. Alguns setores são espaçosos, com corredores largos e boxes grandes; outros têm corredores apertados, boxes menores e muito próximos uns aos outros. Há praça de alimentação e banheiros.

Se há, no Oiapoque, produtos que são vendidos em todos os outros shoppings populares, como roupas, CDs, brinquedos, calçados, acessórios para celular, rádios de pilha, etc., por outro lado, apenas no primeiro há produtos eletroeletrônicos de alto valor comercial, com tecnologia avançada, como DVDs portáteis, câmaras digitais, filmadoras etc.

O Xavantes Pop Shopping - que funciona em frente ao Oiapoque - e o Shopping Tupinambás - situado à rua Curitiba, 149 - foram inaugurados um ano depois, em agosto de 2004.

O Xavantes tem apenas um andar, mas sua organização interna, assim como a dos outros shoppings visitados, é confusa. A numeração dos boxes não é linear, não existe sinalização para a localização das saídas, dos banheiros, dos bebedouros e da administração. Não há lanchonete, nem restaurantes. Esse shopping foi ampliado e essa área se diferencia, significativamente, da antiga, tendo melhor estrutura física e apresentação.

O Shopping Tupinambás, por sua vez, situa-se em uma região pouco movimentada do centro de Belo Horizonte, embora esteja próximo do Terminal Rodoviário. Além disso, o acesso ao pedestre é dificultado. Buscando aumentar a movimentação de pedestres na área - atendendo a reivindicação dos empreendedores populares -, a PBH transferiu alguns pontos de embarque e desembarque de ônibus para as proximidades desse shopping. Uma peculiaridade do Tupinambás era a existência de um estacionamento, o que, inclusive, era visto como importante para atrair con-

física, civilmente capaz, que exerce atividade lícita, por conta própria e sem relação de emprego, mediante prévia e expressa autorização da Secretaria Municipal da Coordenação de Gestão Regional Centro-Sul da Prefeitura Municipal de Belo Horizonte, e abrange camelôs, toreros e artesãos. 
sumidores de classe média, mas ele deixou de funcionar em agosto de 2005.

Diferentemente dos outros shoppings, o Tupinambás possui corredores largos, facilitando a circulação dos consumidores e, além disso, em alguns pontos, foram colocados bancos para descanso, oferecendo maior conforto ao público que frequenta seu espaço. Esse shopping apresenta, ainda, uma particularidade importante: sua grande variedade de mercadorias.

Já o shopping Caetés foi o quarto a ser inaugurado - em dezembro de 2004 - e situa-se à Rua dos Caetés 466, limitado pelas Ruas São Paulo e Rio Janeiro, com entradas pela Avenida Santos Dumont e Ruas Rio de Janeiro e Caetés. Sua localização pode ser considerada como a melhor, em relação aos outros shoppings populares, devido à sua centralidade e à grande movimentação nessas ruas, que concentram várias lojas e linhas de ônibus.

O funcionamento dos shoppings populares se faz de acordo com o Regulamento de Centro de Comércio Popular, que objetivou atender à demanda do comércio informal do município e capacitar os Empreendedores Populares para atuarem no mercado de trabalho. O empreendedor é responsável pelo pagamento dos valores das taxas decorrentes da atividade, além dos encargos previstos no contrato de locação. Além disso, são de sua inteira responsabilidade a identidade e a procedência dos produtos por ele comercializados.

Os shoppings populares são administrados por um Conselho Gestor, composto por três membros não-remunerados: um representante do Município de Belo Horizonte (que exerce a função de Coordenador); um representante do locador; e um representante eleito entre os Empreendedores Populares e Lojistas.

A utilização dos boxes nos shoppings é efetivada mediante autorização da Secretaria Municipal da Coordenação de Gestão Regional Centro-Sul, sendo considerada onerosa, pessoal e intransferível. Essa autorização, no entanto, pode ser revogada a qualquer momento, a crité- rio da Administração Municipal, se a sobrepujar um motivo de interesse público ou se for alterada a destinação para a qual foi permitida, ou por qualquer infração ao disposto no regulamento, não se garantido ao interessado qualquer tipo de indenização.

É responsabilidade do empreendedor popular o pagamento do valor correspondente aos encargos provenientes do funcionamento e da operacionalização tanto da área ocupada quanto das áreas de uso comum do shopping, bem como outros encargos que vierem a ser instituídos pelo Conselho Gestor.

Por fim, é vedado aos empreendedores populares, sob pena de perda de direito da autorização, ceder, arrendar, locar, sublocar, trocar, emprestar e (ou) vender a área objeto da autorização a terceiros, bem como manter o box fechado, por mais de 24 horas, sem autorização do grupo gestor.

Torna-se importante salientar, entretanto, que os camelôs que desenvolviam suas atividades informais nas ruas do centro de Belo Horizonte e foram transferidos para os shoppings populares, com o status de empreendedores, continuam na informalidade. Em sua maioria, estão em plena capacidade produtiva e em condições de inserção no mercado de trabalho formal. A participação desse grupo no mercado mostra que o trabalho informal se transformou numa estratégia para obter algum tipo de rendimento.

\section{ESPAÇO PÚBLICO URBANO: questões e debates}

Um debate que está na agenda acadêmica, mas também na mídia e mesmo no senso comum, desde, pelo menos, os anos 1980, refere-se aos usos e às apropriações do espaço público contemporâneo. Talvez o diagnóstico mais comum se refira à ideia de seu declínio e, decorrente daí, sua privatização. Embora essa ideia de privatização possa nos remeter, num primeiro momento, apenas ao fechamento de espaços que 
seriam públicos (via, por exemplo, construção de condomínios fechados, portões em praça, etc.), no caso das regiões centrais das grandes cidades, de uma maneira geral, os camelôs foram acusados de privatizar um espaço que seria de uso geral. Para se discutir sobre a política da PBH de transferência dos camelôs para os shoppings populares, é fundamental refletir sobre o espaço público.

É comum que esse espaço seja pensado no sentido de esfera pública. Aqui, porém, a noção será tratada levando-se em conta o espaço físico e urbano. Se a esfera pública refere-se à representação e à ação, mas não, necessariamente, a um espaço físico real (ou concreto), neste artigo a discussão se volta para as representações, ações, interações e sociabilidades que ocorrem no espaço urbano. " "Embora o espaço público tenha uma dimensão social e política nãoespacial - encontro de ideias, discursos, projetos sociais -, essa dimensão se manifesta no espaço físico." (Segovia; Oviedo, 2002, p.71); ou seja, remete ao espaço e à esfera da representação.

O espaço público, pelo menos idealmente, é o lugar da diferença, da heterogeneidade, do encontro com estranhos. Tal definição decorre do fato de que esse espaço é (ou deveria ser) aberto e, daí, é acessível a todos. Por outro lado, esse acesso não significa ausência de conflito; pelo contrário, muitas vezes, as diferenças no uso do mesmo espaço podem revelar desigualdades e hierarquias.

Pode-se afirmar que é consensual a ideia de que a modernidade urbana tem início com a revolução urbana de Paris, arquitetada por Haussmann no século XIX, cuja marca é o bulevar (Benjamin, 1985; Berman, 1986; Frúgoli, 2000; Caldeira, 2003; Leite, 2004). Os bulevares, com seus cafés envidraçados, permitiam que as pessoas vivessem, a um só tempo, a cena pública e o domínio privado. Nas palavras de Berman (1986, p.147), era: “... um espaço privado em público, onde eles podiam dedicar-se à própria intimidade, sem estar fisicamente sós”. De dentro do café, era possível ter contato, pelo menos

\footnotetext{
9 Sobre isso, ver Segovia e Oviedo, 2002; Leite, 2004;
} Andrade e Jayme, 2006; Serpa, 2007, entre outros. visual, com o "outro", o diferente, no mais das vezes, desigual.

Apesar de serem criticados por seu caráter higienista e de "embelezamento estratégico" (Benjamin, 1985a), não se pode negar que os bulevares tenham sido, de fato, apropriados por um sem número de pessoas, que circulavam a pé e anônimas entre a multidão, por vezes num "andar à toa", olhando vitrines, por vezes em manifestações políticas, por vezes consumindo, em lojas de departamento ou nos cafés. Embora tivesse sido projetado para a elite, via-se também, nesses espaços, alguma interação entre os diferentes, não só por trás dos vidros dos cafés, como em Os olhos dos pobres, de Baudelaire, ${ }^{10}$ mas também circulando pelas ruas, já que, embora tenha destruído bairros inteiros para implantar o sistema de bulevares, Haussmman teria, também, possibilitado que as pessoas expulsas desses lugares frequentassem aquele centro: ${ }^{11}$

No espaço da cidade moderna, diferentes cidadãos negociam os termos de suas interações e de fato interagem socialmente a despeito de suas diferenças e desigualdades. Esse ideal de cidade aberta tolerante às diferenças sociais e às negociações em encontros anônimos cristaliza o que chamo de espaço público moderno e democrático (Caldeira, 2003, p.307).

O que Teresa Caldeira chama de "espaço público moderno e democrático” é, certamente, a definição ideal desse espaço. Ao circular pelas ruas daquela Paris do século XIX, parece que Baudelaire não encontrou, exatamente, essa tolerância à diferença; antes, enxergou conflito e intolerância; ou seja, o espaço público, exatamente por ser aberto a todos - portanto, aberto a sujeitos em diferentes posições na hierarquia social -, é, também, o lugar do conflito. Como afirmam Andrade e Jayme (2006), os espaços 10 Ver a reflexão de Berman (1986, p.146-150) sobre esse poema.

11 "A família em farrapos, do poema baudelaireano, sai detrás dos detritos, pára e se coloca no centro da cena. O problema não é que eles sejam famintos ou pedintes, o problema é que eles não irão embora. Eles também querem um lugar sob a luz. [...] Esta cena revela algumas das mais profundas ironias e contradições da vida moderna. [...] As transformações físicas e sociais que haviam tirado os pobres do alcance da visão, agora os trazem de volta diretamente à vista de cada um." (Berman, 1986, p.148). 
públicos são abertos a todos e, portanto, são lugares onde pode ocorrer conflito e, muitas vezes, um grupo pode constranger a presença de outro. Além disso, podem questionar hierarquias estabelecidas em outras esferas, possibilitando novas interações.

Se há algum consenso sobre o uso do espaço público e da própria cidade nessa etapa da modernidade, cujo símbolo seria a Paris haussmaniana, não se pode dizer o mesmo em relação a esse uso no contexto contemporâneo. Parte da bibliografia que vem refletindo sobre esse tema aponta para o declínio (e, mesmo, a morte) ou privatização do espaço público (Sennett, 2002; Caldeira, 2000; Serpa, 2007, entre outros).

Há, por outro lado, autores que, a partir de pesquisas empíricas, demonstram que é necessário estar atento para não "naturalizar" ou universalizar essa ideia de morte do espaço público, na medida em que perceberam a vitalidade de diversos espaços públicos, como praças e parques em Belo Horizonte (Almeida, 2001; Teixeira, 2003; Góis, 2003) ou, por outro lado, a possibilidade de "contra-usos" de lugares enobrecidos, por pessoas que estariam constrangidas de os frequentarem, devido a barreiras simbólicas e reais (Leite, 2004).

Esse debate é instigante, já que, se, por um lado, é possível relativizar a ideia de morte do espaço público, percebendo que existem diversos lugares que realmente têm usos os mais variados - embora, muitas vezes, se note, nesses locais, a busca por uma sociabilidade entre iguais -, por outro lado, não se pode negar o fato de que há espaços aos quais certas camadas da sociedade definitivamente não têm acesso, mesmo que as barreiras sejam simbólicas, conforme afirma Serpa (2007) em relação aos parques das cidades contemporâneas, que, para o autor, ultimamente teriam semelhança com os shopping centers.

Se o projeto haussmmaniano de cidade voltava os olhos para o pedestre que andava pelos bulevares em meio à multidão, em meados do século XX, o bulevar teria dado lugar às rodovias. Agora, as ruas não seriam mais para os pedestres, mas para os carros. Com isso, perderse-ia a interação, o encontro com a diferença. As pessoas estariam protegidas pela lataria dos carros ou pelos sistemas de vigilância dos prédios, dos condomínios fechados, dos shopping centers.

Os autores que advogam o colapso da vida pública defendem, então, que, ao ser "fechada" aos pedestres, a rua teria se tornado um lugar perigoso. Se as pessoas não estão nas ruas, estão em outro lugar, nos chamados "enclaves fortificados" (Davis, 1993; Caldeira, 2003), cujas representações mais bem acabadas seriam o condomínio fechado e o shopping center, lugares frequentados e apropriados por "iguais". A rua, nessa nova configuração de cidade, seria o lugar do "outro", aquele que não tem espaço nesses "pseudoespaços públicos”, como preconizam Davis (1993) e Caldeira (2003).

Os autores que buscam problematizar o diagnóstico de implosão do espaço público o fazem, em geral, com base em pesquisas que apontam não para o fim da sociabilidade nas ruas, parques e praças, mas para a mudança dessa sociabilidade. Lisboa (2006), por exemplo, em uma pesquisa sobre os surdos ${ }^{12}$ de Belo Horizonte, mostra como a Praça Sete de Setembro é fundamental como espaço de interação e de construção e manutenção de uma possível identidade dessas pessoas surdas. Diariamente, eles se encontram nessa praça, que abriga também aposentados que jogam dama ou conversam à toa, engraxates, pessoas que estão apenas de passagem, além de ela ser, tradicionalmente, espaço de manifestações políticas e de representações artísticas. Essa praça é, portanto, um espaço de interações e de convivência entre estranhos e, também, lugar identitário, que tem vitalidade. Além da Praça Sete, existem, em Belo Horizonte, outros tantos espaços públicos que são apropriados pelos cidadãos, seja para fazer ginástica, caminhar, namorar ou pernoitar.

Não se pode negar, no entanto, que a circulação e a sociabilidade que ocorrem nesses lugares hoje são diferentes daquelas que aconteci-

${ }^{12}$ Os surdos, em sua maioria, não consideram a surdez como deficiência; portanto, se denominam surdos. Ver Lisboa (2006). 
am no século XX, tanto pelo medo do crime, pôs como pela intolerância à diferença, que faz, por exemplo, com que, em uma mesma praça, frequentadores de classe média e moradores da favela do entorno até se cruzem, mas não se relacionem, a não ser numa interação violenta ou de prestação de serviços. Assim sendo, mudou a maneira de apropriação dos espaços públicos, mas isso não significa que ela não exista:

... os espaços públicos não foram renegados, mas seus usos e as interações tornaram-se perpassados por uma conduta mais vigilante e temerosa e, em muitos casos, defensiva e mesmo segregacionista em relação ao estranho. Outra mudança foi o crescimento do desemprego e, principalmente, da informalidade, que transformaram alguns espaços públicos, principalmente os das áreas centrais, em grandes áreas de comércio e de sobrevivência ou até mesmo de moradia. (Andrade; Jayme 2006, p.4)

Como foi apontado no primeiro tópico deste texto, um fenômeno comum nas grandes cidades, desde, pelo menos, a década de 1960, foi a criação de novas centralidades, o que, provavelmente, está vinculado à mudança na forma de apropriação dos espaços públicos. Com isso, as regiões centrais, antes lugares de permanência e circulação de diferentes grupos, passaram a ser vistas como o lugar do "outro". Transeuntes apressados e sempre de passagem, consumidores pobres - já que o comércio mais sofisticado foi transferido para os shoppings ou para as novas centralidades -, moradores de rua, prostitutas, camelôs etc. Paralelamente, várias edificações da região vinham sofrendo um processo de deterioração, e o centro, outrora símbolo da modernidade, com suas avenidas largas e retas, para usar a imagem de Drummond, com seus prédios monumentais, foi perdendo a aura moderna e aquele público com maior capital cultural e econômico.

\section{POLÍTICAS DE REQUALIFICAÇÃO: o caso de Belo Horizonte}

Se a cidade moderna tem como paradigma a indústria " e, portanto, o trabalho ", a cidade pós-moderna pode ser vista como centro de consumo e entretenimento. Algumas metrópoles buscaram, a partir da revitalização de suas áreas centrais e da ressignificação dos espaços urbanos, ${ }^{13}$ atrair novos capitais e outros interesses para seus habitantes e consumidores, como o turismo, entretenimentos culturais e inovações no comércio. Com isso, diversas cidades fizeram intervenções urbanas coerentes com a adaptação ao novo marco da globalização econômica, chamadas de revitalização urbana, requalificação urbana, gentrificação, ${ }^{14}$ entre outros termos (Featherstone, 1995; Zukin, 2000; Frúgoli, 2000; Leite, 2004).

Essas políticas de revitalização se apropriam, culturalmente, das imagens das cidades, com o objetivo de atribuir novos sentidos ao passado e, muitas vezes, têm um caráter segregador e higienizador, mas, por outro lado, se esse caráter a princípio pudesse esvaziar o sentido público desses espaços, seus usos e contra-usos poderiam reativá-los como públicos (Leite, 2002, 2004). Para o autor, à "desapropriação de sujeitos" dos locais revitalizados pode corresponder a reapropriação desses espaços por outros sujeitos, que podem alterar a paisagem e conferir outros sentidos a esses lugares. Enfim, nem sempre esses processos resultam em uma reordenação lógica dentro do planejado pelas políticas urbanas. As formas cotidianas de (re) apropriação dos espaços publicizam e politizam as diferenças, atribuindo sentidos a tais espaços e qualificando-os como públicos.

As discussões contemporâneas sobre política urbana apontam para mudanças conceituais e metodológicas significativas no que se refere à reabilitação urbana, que passa a ser um instrumento de planejamento, com o papel de estabelecer a continuidade nos processos de apropriação dos espaços, incorporando as demandas físicas e sociais contemporâneas às referências sim-

13 São comuns as (re) apropriações de antigas fábricas desativadas e de estações de trem, símbolos, por excelência, da modernidade.

${ }^{14}$ A gentrificação pressupõe uma reapropriação residencial (por grupos de maior poder aquisitivo), o que, algumas vezes, demanda a desapropriação de antigos moradores, nessas áreas centrais requalificadas. 
bólicas do passado e às potencialidades futuras, com um sentido de persistência temporal.

De acordo com Arroyo (2004), ao ser recuperado, o patrimônio torna-se mais acessível. Assim, uma área considerada degradada, subutilizada ou utilizada apenas como passagem, pode ser potencializada e se converter em espaço de aglutinação e de apropriação de diferentes grupos sociais, tornando-se referência de toda a cidade. A reforma da Praça da Estação esteve inserida no projeto Centro Vivo - Programa de Requalificação da Área Central - da Prefeitura de Belo Horizonte e, além de ter seu conjunto arquitetônico recuperado, passou a abrigar o Museu de Artes e Ofícios. Esse tipo de intervenção, por um lado, vai ao encontro dessa busca de "pós-modernização" das cidades, que torna os museus mais acessíveis, além de apontar modos de vida cotidianos como de interesse cultural. Esse museu, por exemplo, focaliza o trabalho. A frase de abertura do seu site é a seguinte: "Museu de Artes e Ofícios é um espaço cultural criado para contar a história e as relações sociais do trabalho no Brasil" (www.mao.org.br). Ao discutir sobre as culturas pós-modernas da cidade, Featherstone (1995), retomando Baudrillard, aponta para o fato de que essas cidades estariam saturadas de imagens, de forma que tudo passa a ser visto como objeto de interesse, de "observação turística". Tanto o formato Disneyworld como os museus, agora com estoque renovado de objetos, podem (e devem) ser preservados, como, por exemplo, uma mina de carvão.

Por outro lado, ao mesmo tempo em que a Praça da Estação passa a abrigar um museu, retoma seu uso tradicional de praça pública. O Projeto Centro Vivo recuperou, do ponto de vista arquitetônico, outras ruas da região central, mas sem modificar o seu uso (Moreira, 2008). A criação dos shoppings populares foi uma iniciativa que contribuiu para retomar o uso de áreas que estavam abandonadas. O Oiapoque, por exemplo, situa-se em uma fábrica de cerveja abandonada, cuja edificação foi tombada, em 1991, pelo Conselho Deliberativo do Patrimônio Histórico, e adquirida, em leilão, por um em- presário do ramo de transportes, com o intuito de construir ali um "camelódromo". Desde então, passam por aquele edifício centenas de pessoas, diariamente.

O Hipercentro de Belo Horizonte ${ }^{15}$ funciona como eixo integrador com os demais espaços metropolitanos, especialmente devido à circulação diversificada de transportes coletivos. $\mathrm{O}$ local tem acesso fácil e boa infraestrutura, com comércio diversificado e amplo setor de serviços, além de uso residencial. Em 2000, o Hipercentro foi definido pelo Plano Diretor da Prefeitura de Belo Horizonte como:

... uma área preferencial para a implantação de
projetos especiais, visando à preservação do
patrimônio e à melhoria de sua qualidade
ambiental, das condições de segurança e de circu-
lação para pedestres; um local de acesso privile-
giado para o transporte coletivo e para o resgate
das calçadas como espaço para circulaçãa de pe-
destres; uma cárea da cidade que, pela grande con-
centração de edificaçôes e espaços de interesse
cultural, torna-se privilegiada para a implantaçãa
de políticas de valorização, proteção e promâão
do patrimônio (Belo Horizonte, 2000, p.13-14).

Se há uma definição do que seja essa área, pode-se dizer que ela é apenas formal, na medida em que, concretamente, o que se percebe é uma infinidade de significados atribuídos a esse espaço. Tal região é vista, a um só tempo, como espaço degradado, que necessita de recuperação; como lugar perigoso para se transitar, por causa da criminalidade; como espaço de residência, de trabalho, de manifestações políticas e artísticas etc.

Ao fazer um "inventário" dos problemas que envolvem a área, o Plano de Ação para o Hipercentro aponta que, para as pessoas que frequentam o local ou ali vivem, a violência seria um dos principais problemas. Além disso, porém, a escassez de opções de lazer, o fechamento do comércio por volta das dezenove horas, os altos índices de poluição sonora, atmosférica e visual, a ausência de padronização e a inadequação do mobiliário urbano, as atividades que transbor-

${ }^{15} \mathrm{O}$ Hipercentro é considerado como a área delimitada pelas Avenidas Bias Fortes, Praça Raul Soares, Avenida Álvares Cabral, Rua dos Timbiras, Parque Municipal, Avenida Francisco Sales, Rua Itambé, Rua Sapucaí, Avenida do Contorno e Rodoviária. 
dam os estabelecimentos comerciais (mesas, bancas e vitrines), a dificuldade de carga e descarga, a disputa do espaço viário entre pedestres, veículos coletivos e particulares que circulam pela área, a ausência de atratividade e de comunicação visual das fachadas e os conflitos que envolviam os camelôs, os comerciantes das lojas, os moradores e os frequentadores da região seriam vistos como seus problemas mais sérios.

O Centro Vivo - que teve início em 2004 e ainda está em vigor ${ }^{16}$ - tem como uma das metas o reforço do Hipercentro como lugar simbólico da cidade e do Estado, a partir da valorização da diversidade de suas atividades, da consolidação da área como espaço de encontro de todos, da melhora das condições de funcionamento do comércio local, do investimento em ações que visem à segurança da área e da retomada do centro para moradia.

Dentro das ações desencadeadas por esse Programa, foi desenvolvido o projeto $E$ bom trabalhar no Centro de BH, que teve como objetivos: a melhoria da oferta de empregos no centro da cidade; a capacitação de trabalhadores do comércio; a organização do comércio na região central, tornando-o mais adequado e atrativo para o consumidor; a promoção da inclusão de trabalhadores no mercado formal, por meio da capacitação; e a criação de melhores condições de trabalho para o centro, com oferecimento de creches para filhos de mães aí empregadas e de instalações de qualidade para os comerciantes.

As primeiras intervenções direcionadas à organização do comércio no Hipercentro datam de julho de 2003, quando foi determinada a retirada dos camelôs das ruas da região central, pelo Código de Posturas. Essa determinação baseouse em debates ocorridos na II Conferência de Política Urbana, realizada em 2002, na qual se discutiu a transferência dos ambulantes para os shoppings populares, que seriam instalados em

${ }^{16}$ Embora o Programa Centro Vivo tenha sido lançado em 2004 , ele engloba ações que foram realizadas antes, como as requalificações da Praça Sete e da Praça da Estação, realizadas entre 2002 e 2003, e a transferência dos camelôs para os shoppings populares, que teve início em 2003. locais de grande circulação de pessoas.

Além da transferência dos camelôs e toreros para esses shoppings populares, outras ações relacionadas à requalificação do centro, que fazem parte do Plano Diretor da metrópole, já foram executadas ou encontram-se em andamento, entre as quais se destacam: a recuperação das calçadas, a recomposição paisagística, a melhoria da iluminação e a recuperação do patrimônio histórico e cultural. À medida que foram sendo executados os projetos de requalificação do espaço público, como a transformação, em praça, dos quarteirões fechados das Ruas Carijós e Tamoios, antes ocupados pelos camelôs, alguns resultados foram percebidos, como, por exemplo, o aumento na procura por imóveis residenciais no centro.

Ao discutir sobre as políticas de requalificação no centro de São Paulo, Frúgoli $(1999,2000)$ afirma que a recuperação da área central é, por si só, insuficiente, do ponto de vista da inserção das classes populares, e o que vem ocorrendo, sistematicamente, nas cidades que desenvolvem esse tipo de trabalho, é a exclusão de vários atores sociais, entre os quais os camelôs, os moradores de rua e os desempregados. No caso de Belo Horizonte, houve, de fato, a retirada dos camelôs das ruas do centro. Os shoppings populares, porém, foram construídos na região central. Por certo, essa foi uma forma menos agressiva de transferência desses trabalhadores, porque, em algumas cidades, a ideia era de que os chamados "camelódromos" ficassem longe da área central (Frúgoli, 1995, 2000).

As políticas de revitalização da segunda metade do século XX, que ocorreram em diferentes cidades do mundo, pareciam ter em comum a ideia de enobrecimento ou embelezamento de regiões antes degradadas, tornando-as aptas a serem apropriadas por uma elite que as teria abandonado. Se, em cidades como Nova Iorque, esses espaços foram também retomados como locais de moradia, no Brasil, foram comuns os projetos que transformavam essas áreas apenas em espaços de "consumo cultural", com bares "chiques", boates, casa de shows etc., abertos nas 
antigas edificações recuperadas. Dessa forma, uma das principais críticas a essas políticas se referia ao fato de que elas resultariam em segregação social da população de baixa renda que residia ou trabalhava nessas regiões.

O Projeto Centro Vivo parece ter levado em consideração essa crítica e, mesmo que não sem conflito, vem buscando minimizar esse caráter higienizador e segregador comum aos projetos das décadas de 1990. Além disso, até o momento, o projeto não tem modificado os diferentes tipos de uso da região central, transformando o centro em uma região de consumo cultural, como ocorreu com o bairro do Recife ou o Pelourinho (em Salvador), para ficar com apenas dois exemplos. No caso da Rua Caetés, por exemplo, Moreira (2008, p.79) diz que se pode perceber, ali “... a manutenção das características ditas populares desse espaço, bem como da predominância do comércio e dos serviços que atendem a essa população, mesmo após as ações de revitalização ali realizadas". Talvez a novidade, no caso de Belo Horizonte, é que o Projeto não seja dirigido ao turista, mesmo que os aspectos visuais tenham sido levados em conta (Moreira, 2008).

\section{SHOPPINGS POPULARES: uma solução?}

bém, levado uma população de maior poder aquisitivo a uma região vista, tradicionalmente, como marginal. Além disso, de uma maneira geral, os comerciantes que estão no Shopping Oi parecem satisfeitos com seu novo local de trabalho, já que, de fato, é um estabelecimento por onde passam milhares de consumidores, pertencentes a diferentes camadas sociais. $\mathrm{O}$ aspecto dessas mudanças que precisa ser mais enfatizado e discutido pelos formuladores da política de requalificação referese aos outros centros comerciais populares que, até o momento, não têm a mesma situação do Oiapoque, mesmo que estejam " como o Xavante e o Caetés " na mesma região. A população de Belo Horizonte, em geral, frequenta o Shopping Oi e não os shoppings populares.

O shopping Oiapoque é bem divulgado, com propagandas veiculadas em diversos meios de comunicação, além de ter um jornal de anúncios distribuído gratuitamente e um site. Hoje há, inclusive, um cartão de crédito do próprio shopping: Credi Oiapoque. ${ }^{17}$ Cabe perguntar: por que não os outros? O que faz com que um estabelecimento situado em frente ao Oiapoque não tenha o mesmo apelo para atrair público consumidor?

Parece-nos que a ideia de retirar os camelôs das ruas do centro, sem retirá-los do centro, foi uma solução bem pensada, porque buscou não excluir esses trabalhadores. Além disso, pelo menos o shopping Oiapoque parece ter tido bons resultados, posto que muitos empreendedores populares afirmam que foram contrários ao projeto, especialmente pelo medo de perder a clientela, mas que, hoje, estão de acordo, ${ }^{18}$ por terem mantido clientes e terem melhor condição de tra-

17 “... único cartão de crédito feito exclusivamente para atender os consumidores do local. Para fazer o cartão, é muito fácil: basta o consumidor apresentar o CPF, carteira de identidade, comprovante de renda (folha de pagamento) e endereco (como uma conta de água, luz ou telefone, por exemplo). Para os autônomos, além desses documentos descritos, o comprovante de renda será os três últimos extratos bancários. Toda proposta de cartão será analisada mediante as condições e/ou restriçóes de crédito do solicitante. O cartão demora sete dias para ficar pronto e não possui anuidade.“ (www.shoppingoiapoque.com.br). ${ }^{18} \mathrm{Na}$ verdade, é preciso explicitar que há muita ambiguidade na representação desses trabalhadores, com referência à transferência. A rua é representada, a um só tempo, como o lugar do companheirismo, da solidariedade, da amizade, e como local do conflito e do risco. 
balho, exatamente por não estarem na rua. Talvez um aspecto importante seja discutir políticas para os outros shoppings populares, pensando em ações que possam contribuir para que também eles sejam apropriados pelos consumidores.

Iniciamos este texto perguntando se a transferências dos antigos camelôs para os shoppings populares teria contribuído para o uso mais heterogêneo da região central de Belo Horizonte. Como o Programa Centro Vivo, ao qual essa ação se vincula, está em curso, ainda é cedo para se afirmar se há um uso mais diversificado e diferenciado desse espaço.

(Recebido para publicação em julho de 2009) (Aceito em junho de 2010)

\section{REFERÊNCIAS}

ALMEIDA. Rachel de Castro. Espaço público e paisagem urbana: um estudo sobre duas praças de Belo Horizonte. 2001 124 f. Dissertação (Mestrado em Ciências Sociais) - Programa de Pós-graduação em Ciências Sociais da Pontifícia Universidade Católica de Minas Gerais, Belo Horizonte, 2001.

ANDRADE, Luciana; JAYME, Juliana; ALMEIDA, Rachel. Espaços públicos: novas sociabilidades, novos controles. In: ENCONTRO ANUAL DA ANPOCS, 28, 2004, Caxambu, MG, Anais... Caxambu,MG: 2004

As praças como espaços públicos de grandes cidades. In: REUNIẪO BRASILEIRA DE ANTROPOLOGIA, 25, 2006, Goiânia, GO. Anais..., 11 a 14 jun. Goiânia:GO: 2006 .

ARROYO, Michele Abreu. Reabilitação urbana integrada e a centralidade da Praça da Estação. 2004. 158 f. Dissertaç̃o (Mestrado em Ciências Sociais) - Programa de Pós-graduação em Ciências Sociais da Pontifícia Universidade Católica de Minas Gerais, Belo Horizonte, 2004.

BELO HORIZONTE. Prefeitura Municipal. Secretaria Municipal de Atividades Urbanas - Departamento de Fiscalização. Lei $n .^{\circ}$ 3.841. Reorganiza o processo de licenciamento de bancas de camelôs nos logradouros públicos e dá outras providências. 17 de ago. de 1984

. Prefeitura Municipal. Lei no. 5872 de 14 de Março de 1991. Estabelece a Região da Savassi, disciplina normas de posturas e dá outras providências. Diário Oficial do Município, 14 mar. 1991.

Prefeitura Municipal. Plano de ação para o Hipercentro. Belo Horizonte:PBH, 2000. p.11,13-14,

. Prefeitura Municipal. Decreto 11424, de 22 de ago. 2003. Declara de utilidade pública para fins de desapropriação, imóveis situados na Primeira Seção Urbana, nesta capital. Diário Oficial do Município, 24 ago. 2003.

BENJAMIN, Walter. Paris, capital do século XIX. In: KOTHE, Flávio (Org.) Walter Benjamin. São Paulo: Ática, 1985. p.30-43.

. A Paris do Segundo Império em Baudelaire. In:
KOTHE, Flávio (Org.) Walter Benjamin. São Paulo: Ática, 1985b. p.4-122.

BERMAN, Marshall. Tudo que é sólido desmancha no ar: a aventura da modernidade. São Paulo: Cia. das Letras, 1986. $360 \mathrm{p}$.

CALDEIRA, Teresa Pires do Rio. Cidade de muros: crime, segregação e cidadania em São Paulo. São Paulo: Ed. 34/ EDUSP, 2003. 400 p.

CAMPICI, C. P. F; FONSECA, C. G.; PEIXOTO, D. A. GONZAGA, M. M. Interações cotidianas e produção de sentidos no Hipercentro de Belo Horizonte. In: ENECULT tidos no Hipercentro de Belo Horizonte. In: ENECULT -
Encontro de Estudos Multidisciplinares em Cultura, 2, Salvador. Bahia: 2006. Disponível em: www.cult.ufba.br/ enecul2006/milene_gonzaga.pdf. Acesso em: 04 set., 2008.

CASTRO, Maria Aparecida. O camelô na cidade de Belo Horizonte: informalidade e identidade. 2003. 94 f. Dissertação (Mestrado em Ciências Sociais) - Programa de Pós-graduação em Ciências Sociais da Pontifícia Universidade Católica de Minas Gerais. Belo Horizont, 2009.

DAVIS, Mike. Cidade de quartzo: escavando o futuro em Los Angeles. São Paulo: Scritta Editorial, 1993. 382 p.

DURÃES, Bruno José Rodrigues. Uma nova configuração da informalidade: o 'camelô global' ou de produtos tecnológicos. In: CONGRESSO BRASILEIRO DE SOCIOLOGIA, 13, 2007, Recife. Anais... Recife: 2007.

FEATHERSTONE, Mike. Cultura de consumo e pós-modernismo. São Paulo: Studio Nobel, 1995. 223 p.

FIGUEREDO, Fernanda Odilla; MORAIS, Mariana Ramos. A elite no camelódromo: o inesperado efeito da construção do shopping popular em Belo Horizonte. In: ENCONTRO NACIONAL DA ANPUR, 8. Belo Horizonte, 2004.

FRÚGOLI, Heitor. São Paulo: espaços públicos e interação social. São Paulo: Marco Zero, 1995. 111 p.

. A questão dos camelôs no contexto da revitalização do centro da metrópole de São Paulo. In: SOUZA, M. A. A. de; LINS, S. C.; SANTOS; M. P .C.; SANTOS, M.C. (Org.). Metrópole e globalização. São Paulo: CEDESP, 1999, p. 151-165.

Centralidade em São Paulo: trajetórias, conflitos e negociações na metropóle. São Paulo: Cortez, 2000. 264 p.

GÓIS, Aurino J. Parque Municipal de Belo Horizonte: público, apropriações e significações. 2003. 122 f. Dissertação (Mestrado em Ciências Sociais) - Programa de Pós-graduação em Ciências Sociais da Pontifícia Universidade Católica de Minas Gerais. Belo Horizonte, 2003.

GONÇALVES, Marcelino Andrade; THOMAZ JÚNIOR, Antônio. Informalidade e precarização do trabalho: uma contribuição à geografia do trabalho In: Scripta Nova Revista Electrónica de Geografía y Ciencias Sociales. Barcelona, Universidad de Barcelona, v.6, n.119 (31), ago. 2002. Disponível em: www.ub.es/geocrit/sn/sn119-33.htm. Acesso em: 12 ago., 2008

JAYME, Juliana Gonzaga; NEVES, Magda de Almeida. Trabalho, identidades e políticas de requalificação em Belo Horizonte: camelô ou empreendedor popular? In: REUNIÃO BRASILEIRA DE ANTROPOLOGIA, 26, 2008, Porto Seguro, 1-4 jun. 2008.

JOSEPH, Isaac. Paisagens Urbanas, coisas públicas. Caderno CRH: revista do Centro de Recursos Humanos da UFBA, Salvador, n.30/ 31, p. 11-37, jan./dez, 1999.

LEITE, Rogério Proença. Contra-usos e espaço público: notas sobre a construção social dos lugares na Manguetown. Revista Brasileira de Ciências Sociais, São Paulo, v.17, n.49, p.115-135, jun. 2002.

Contra-usos da cidade: lugares e espaço público na experiência urbana contemporânea. Campinas: Ed Unicamp; Aracaju: Ed. UFS, 2004. 376 p. 
LEMOS, Celina Borges. A conștrução simbólica dos espaços da cidade. In: MONTE-MÓR, R. L. M. (Org.). Belo Horizonte: espacos e tempos em construção. Belo Horizonte: CEDEPLAR/PBH, 1994. p. 29-51.

Antigas e novas centralidades: a experiência da cultura do consumo no Centro Tradicional de Belo Horizonte. 2003. Tese. (Doutorado em Ciências Sociais) - Programa de Pós-graduação em Ciências Sociais, Universidade Estadual de Campinas. 2003.

LISBOA, Camila Barcelos. As imagens do silêncio: uma análise sócio-antropológica das interações entre surdos de Belo Horizonte. 2007. Dissertação (Mestrado em Ciências Sociais) - Programa de Pós-graduação em Ciências Sociais, Pontifícia Universidade Católica de Minas Gerais. Belo Horizonte, 2007.

MACHADO, Rosana Pinheiro. A rua como estilo de vida: práticas cotidianas na ocupação do centro de Porto Alegre por camelôs. Iluminuras: etnografias nas Ruas, n.62. Porto Alegre: Banco de Imagens e Efeitos Visuais, PPGAS/UFRGS, 2004, p.1-39 Disponível em: www.iluminuras.ufrgs.br/apresenta-revista.php?cod_rev=33. Acesso em: 02 set. 2008.

MOREIRA, Corina Maria Rodrigues. Patrimônio cultural e revitalização urbana: usos, apropriações e representações da Rua dos Caetés, Belo Horizonte. 2008. Dissertação (Mestrado em Ciências Sociais) Programa de Pós-graduação em Ciências Sociais. PUC, Minas. Belo Horizonte, 2008.

MUSEU DE ARTES E OFÍCIOS. Disponível em: www.mao.org.br. Acesso em: 03 set., 2008.

NEVES, Magda de Almeida. Trabalho e cidade: categoria ocupacionais e informalidade na Regiáo Metropolitana de Belo Horizonte. Relatório de Pesquisa Fapemig. Belo Horizonte, abr. 2007.
; JAYME, Juliana; ZAMBELLI, Paulina. Trabalho e cidade: os camelôs e a construção dos shoppings populares em Belo Horizonte. In: ENCONTRO ANUAL DA ANPOCS, 30, 2006. Caxambu. Anais.... São Paulo: 2006.

SEGOVIA, Olga; OVIEDO, Enrique. Espacios Públicos en la Ciudad y el Barrio. In: $\quad$; DASCAL, Guillermo (Ed.) Espacio público, participación y ciudadanía. Santiago de Chile: Ediciones Sur, 2002. p. 51-69.

SENNETT, Richard. O declínio do homem público: as tiranias da intimidade. São Paulo: Cia. das Letras, 2002. 447 p.

SERPA, Ângelo. O espaço público na cidade contemporânea. São Paulo; Contexto: Salvador: Editora UFBA, 2007. $208 \mathrm{p}$.

SHOPPING OIAPOQUE. Disponível em: www.shoppingoia poque.com.br. Acesso em: 04 set. 2008

SOUZA, Marcelo Lopes de. O desafio metropolitano: um estudo sobre a problemática sócio-espacial nas metrópoles brasileiras. Rio de Janeiro: Bertrand Brasil, 2000. 368 p.

ZAMBELLI, Paulina. O trabalho informal dos camelôs na região central de Belo Horizonte e a transferência para os shoppings populares, 2006. (Mestrado em Ciências Sociais) "Programa de Pós-graduação em Ciências Sociais, Pontifícia Universidade Católica de Minas Gerais. Belo Horizonte: 2006.

ZUKIN, Sharon. Paisagens urbanas pós-modernas mapeando cultura e poder. In: ARANTES, Antonio (Org). O espaço da diferença. Campinas: Papirus, 2000. p. 81-102. 
CITY AND PUBLIC SPACE: popular malls in Belo Horizonte

\author{
Juliana Gonzaga Jayme \\ Magda de Almeida Neves
}

This paper discusses whether, and to what extent, the construction of popular shopping malls - one of the actions of the program Living Center, in Portuguese Centro Vivo - which aimed to remove street vendors from the streets of downtown Belo Horizonte , contributed to maximizing the more heterogeneous use of these spaces. To this end, the text will be divided into four topics. At first, a history of the presence of street vendors in Belo Horizonte will be made, in order to situate them in time, and, simultaneously, reflect on their more recent appropriation of the city center.In the second, the idea and ideal of public space, as thought in the modernity, will be discussed. Then the discussion turns to public space in contemporary society, from the revitalization policies in general - common, from the late 1980s - and the case of Belo Horizonte. Finally, in seeking a conclusion, the relationship between the subjects who were transferred to the popular shopping malls - the street vendors - and the scene in question: the center of Belo Horizonte will be resumed.

KEYWORDS: city, public space, urban revitalization, popular shopping.
VILLE ET ESPACE PUBLIQUE: centres commerciaux populaires a Belo Horizonte

\section{Juliana Gonzaga Jayme \\ Magda de Almeida Neves}

L'objectif de cet article est de voir si, et dans quelle mesure, la construction de centres commerciaux populaires - l'une des actions du programme Centre Vivant- dont l'objectif est de retirer les vendeurs ambulants des rues du centre de Belo Horizonte, a contribué à optimiser l'utilisation de ces espaces de manière plus hétérogène. À cette fin, le texte est divisé en quatre parties. Dans la première, on y fait l'historique de la présence des vendeurs de rue à Belo Horizonte afin de les situer dans le temps et, en même temps, de réfléchir au fait qu'ils se soient appropriés plus récemment le centre-ville. Dans la seconde partie, l'idée et l'idéal de l'espace public, dans la pensée moderne, y sont débattus. S'en suit une réflexion sur l'espace public dans la société contemporaine, à partir des politiques de revitalisation en général - communes à la fin des années 1980 - et le cas de Belo Horizonte. En guise de conclusion, on reprend la relation existante entre les sujets qui ont été transférés dans les centres commerciaux populaires - les camelots - et le scénario en question: le centre de Belo Horizonte.

MOTS-CLÉS: ville, l'espace public, la revitalisation urbaine, des centres commerciaux populaires

\footnotetext{
Juliana Gonzaga Jayme - Doutora em Ciências Sociais pela UNICAMP. Professora e pesquisadora do Programa de Pós-graduação em Ciências Sociais e de Antropologia dos cursos de Serviço Social e Publicidade e Propaganda da PUC-MG. Atua nas seguintes temáticas da Antropologia Urbana: Gênero, Corpo, Identidade, Cidade, Trabalho. Integra os grupos de pesquisa Cultura Urbana, modos de vida e identidade e Cultura e Cidade, da PUC-MG e o grupo Cultura, Memória e Identidade (UNB). Publicou (em co-autoria com L. Andrade e R. Almeida) Espaços públicos: novas sociabilidades, novos controle. Cadernos Metrópole, v. 21, p. 131-153, 2009; Trabalho, identidades e políticas de requalificação em Belo Horizonte (em co-autoria com M. Neves). In: Edson Farias. (Org.). Práticas Culturais nos fluxos e redes da sociedade de consumidores (Brasília: Verbis, 2010, p. 1-486); e do artigo Shoppings populares: ...... In: S.Azevedo; A.L.Nabuco (Orgs.). Democracia participativa:.....(Belo Horizonte: Leitura, 2009).

Magda de Almeida Neves - Doutora em Sociologia. Professora aposentada do Departamento de Ciência Política da UFMG. Professora do Programa de Pós Graduação em Ciências Sociais da PUC-MG. Coordena o grupo de pesquisa /CNPq Trabalho e Cidade. Atua na área de Sociologia, com ênfase em Sociologia do Trabalho, principalmente nos seguintes temas: trabalho, reestruturação produtiva, trabalhadores, relações de gênero, cidadania e sindicalismo, trabalho e cidade. Principais publicações: (em co-autoria com J. G. Jayme). Trabalho, identidades e políticas de requalificação em Belo Horizonte. In: Edson Farias. (Org.). Práticas culturais nos fluxos e redes da sociedade de consumidores. (Brasília: Verbis Editora Ltda., 2010) (em co-autoria com J. Jayme Shoppings populares:... In: S.Azevedo; A. L. Nabuco (Orgs.). Democracia Participativa: ...(Belo Horizonte: Editora Leitura, 2009, p. 143-164). Freitas, Maria Vany e Neves, Magda de A. Cidade e trabalho: as experiências de catadores de papel em Belo Horizonte. In Kemp.V.H e Crivellari, H.M. (Org). Catadores na cena urbana-construção de políticas socioambientais. Autêntica, Ed., Belo Horizonte, 2008. Neves, Magda de A. Dinâmicas de trabalho na cidade: informalidade e autogestão. In: Leite, M. e Araújo,A. (Org). O trabalho reconfigurado-ensaios sobre o Brasil e México. Annablume, Ed. São Paulo, 2009.
} 